\title{
DESCRIPTION OF ELDERLY MENTAL STATUS IN WORK AREA PUSKESMAS PAMPANG MAKASSAR
}

\author{
Ayu Wulandari ${ }^{1}$, Yuliana Syam ${ }^{2}$, Arnis Puspitha $\mathbf{R}^{3}$ \\ 1,2,3 Nursing Study Program, Universitas Hasanuddin Makassar \\ email: a.wulandari13@yahoo.com
}

\begin{abstract}
Introduction:mental status of elderly is an emotional or cognitive state in the elderly is shown by the behavior of the stand. Mental health problems are very important for the elderly and often occurs in the elderly. The incidence of mental disorders in the elderly status is very high. paired mental status in elderly pose a variety of problems that can affect physical health, psychological, social and quality of life of the elderly so that the necessary nursing services for the early detection of mental status disorders that occur among the elderly. Methode: The study design quantitative descriptive survey method. Samples numbered 97 people were selected using cluster random sampling. Primary data was collected by questionnaire the Mini Mental Status Examination (MMSE). Result:T he study of 97 respondents showed that $55.7 \%$ had normal mental status, impaired mental status light there are $29.9 \%$ and $14.4 \%$ of elderly with impaired mental status severe. Based propporsi elderly who suffer from mental status of the most widely experienced by women $(52.4 \%)$, greater in very old age $(100 \%)$, greater in elderly unmarried $(100 \%)$, greater in elderly are not in school $(70.6 \%)$, greater in elderly with a history of self-employed work (44.7\%), and greater in the elderly with a history of rheumatic disease (61.1\%). Conclusions: Mental status of elderly in Puskesmas Kota Makassar Pampang mostly normal. Therefore, elderly mental health need to be detected early to avoid the impact of mental disorders in the elderly.
\end{abstract}

Key words :mental status, elderly

\section{PENDAHULUAN}

Kondisi kesehatan lansia yang rentan terhadap berbagai keluhan fisik yang disebabkan faktor alamiah atau penyakit dengan semakin bertambahnya usia. Keberhasilan pembangunan dibidang kesehatan di dunia termasuk Indonesia menyebabkan Angka Harapan hidup (AHH) yang terus meningkat (Departemen Menteri Kesehatan RI, 2014). Seiring meningkatnya AHH, penduduk usia lanjut juga mengalami peningkatan (Irawan, 2013).

Jumlah lansia di seluruh dunia telah mencapai 901 juta jiwa pada tahun 2015 (United Nations, 2015). Seadangkan jumlah lansia di Indonesia mencapai 20.24 juta jiwa (BPS, 2015). Adapun lansia di Makassar tercatat 45.955 jiwa (Dinas Kesehatan
Makassar, 2014). Berdasarkan data dari Puskesmas Pampang jumlah lansia di wilayah tersebut sangat tinggi yaitu mencapai 2.257 jiwa.

Masalah kesehatan mental dan kesejahteraan emosional sangat penting bagi lansia dan sering terjadi pada lansia. Sekitar 15\% dari lansia yang berusia 60 tahun mengalami gangguan mental. Masalah kesehatan mental yang paling sering terjadi pada lansia yaitu depresi dan demensia. Faktor risiko terjadinya masalah kesehatan mental pada lansia adalah faktor sosial, psikologis, dan biologis. Tingkat kesehatan mental lansia dipengaruhi oleh kehilangan, kemampuan untuk hidup mandiri, hambatan mobilitas fisik, nyeri kronis, kelemahan, penurunan status sosial ekonomi dengan pensiun, atau cacat 
(WHO, 2016).

Tingginya angka kejadian lansia yang mengalami gangguan status mental sedangkan gejala awal dari gangguan status mental sulit untuk dideteksi. Lansia seringkali datang ke pusat pelayanan kesehatan untuk mendapatkan penanganan ketika mengalami gangguan status mental yang cukup berat (Davies \& Craig, 2009). Masyarakat juga belum memiliki kesadaran mengenai penderita gangguan status mental sangat tinggi dan memiliki dampak yang buruk pada kualitas hidup dan kemampuan lansia. Deteksi dini status mental lansia sangat penting dilakukan agar lansia segera diberi penanganan untuk menghindari dampak yang lebih buruk.

Lansia yang mengalami gangguan mental harus diatasi dengan melakukan pengkajian pada lansia kemudian memberikan terapi atau pengobatan (Segal, Qualls, \& Smyer, 2011). Dalam riset yang dilakukan Suyoko (2012) ditemukan bahwa lansia yang mengalami gangguan status mental adalah umur 60-69 tahun, berjenis kelamin perempuan, memiliki tingkat pendidikan yang rendah, tidak bekerja, lansia yang menjadi kepala keluarga, status ekonomi rendah, lansia yang bercerai atau tidak memiliki pasangan, memiliki penyakit kronis seperti diabetes militus, gangguan nyeri sendi dan hipertensi.

Kesehatan mental lansia memiliki dampak pada kesehatan fisik maupun sebaliknya. Gangguan fisik dapat mengakibatkan perubahan status mental (WHO, 2016). Sebagian besar lansia dengan gangguan mental tidak mengeluhkan masalah psikis tapi mereka datang dengan keluhan fisik seperti merasa lelah dan kurang tidur yang dapat mengganggu aktivitas sehari-hari. Sehingga masalah gangguan mental pada lansia sulit dideteksi secara langsung. Distress psikologis yang berkepanjangan dapat dampak yang buruk pada kualitas hidup dan kemampuan lansia (Davies \& Craig, 2009). Deteksi dini status mental lansia sangat penting dilakukan agar lansia segera diberi penanganan untuk menghindari dampak yang lebih buruk.

Penyebaran populasi lansia tidak merata diseluruh bagian wilayah di Makassar. Jumlah Populasi lansia terbesar yaitu di wilayah kerja Puskesmas Pampang dan dan wilayah kerja Puskesmas Rappokalling. Berdasarkan data dari Puskesmas Pampang jumlah lansia sangat tinggi yaitu mencapai 2.257 jiwa. Di Puskesmas Pampang belum terdapat data tentang jumlah penderita gangguan status mental dan belum dilakukan pemeriksaan status mental pada lansia di wilayah kerja Puskesmas Pampang di Kota Makassar.

\section{METODE}

Rancangan penelitian yang digunakan yaitu metode deskriptif. Dengan desain penelitian metode cross-sectional study. Populasi dalam penelitian ini yaitu seluruh lansia yang bertempat tinggal di wilayah kerja Puskesmas Pampang yaitu di kelurahan Pampang, Kelurahan Panaikang dan Kelurahan Karampuang yaitu sejumlah 2.557 jiwa. Adapun teknik sampling yang digunakan yaitu cluster random sampling dan didapatkan jumlah sampel sebesar 97.

Instrument yang digunakan yaitu the Mini Mental Status Examination (MMSE) digunakan dalam menilai stimulasi kognitif untuk menemukan peningkatan signifikan dalam kognisi yang diukur (Fratantoro, 2011). Berdasarkan Uji validitas yang dilakukan dalam penelitian Balqis \& Wati (2014) di dapatkan bahwa reliabilitas kuesioner MMSE yaitu alpha cronbach 0,82. Sedangkan uji validitas kuesioner MMSE dibuktikan secara signifikan berkorelasi dengan berbagai tes lain yang mengukur kecerdasan, memori, dan aspek lain darifungsi kognitif (John, 2000). Dalam hal ini, MMSE merupakan instrument baku sehingga tidak dilakukan uji validitas dan reabilitas. 
Peneliti mendatang ilangsung di tempat tinggal responden (door to door) kemudian memberikan pertanyaan kepada responden dari kuesioner the Mini Mental State Examination (MMSE) untuk menilai status mental lansia di

\section{HASIL}

\section{Karakteristik Responden}

\begin{tabular}{ccc}
\hline $\begin{array}{c}\text { Karakteristik } \\
\text { Responden }\end{array}$ & $\mathbf{f}$ & \% \\
\hline Usia (tahun) & 76 & 78,4 \\
Elderly (60-74 tahun) & 20 & 20,6 \\
Old (75-90) & 1 & \\
Very old (>90) & & 2,0 \\
\hline Jenis Kelamin & 27 & 27,8 \\
Laki-laki & 70 & 72,2 \\
Perempuan & & 1,0 \\
Status Perkawinan & 1 & 52,6 \\
Belum kawin & 51 & 46,4 \\
Kawin & 45 & \\
Duda/janda & & 17,5 \\
Tidak Sekolah & 17 & 49,5 \\
Tidak Tamat SD & 48 & 9,3 \\
Tamat SD & 9 & 6,2 \\
Tamat SMP & 6 & 13,4 \\
Tamat SMA & 13 & 4,1 \\
Tamat PT & 4 & \\
IRT & & 48,5 \\
Wiraswasta & 47 & 39,2 \\
PNS & 38 & 6,2 \\
Pegawai & 6 & 6,2 \\
\hline Riwayadikan & 6 & \\
\hline
\end{tabular}

Tabel 1 Distribusi frekuensi karakteristik lansia diwilayah kerja Puskesmas Pampang $(\mathrm{n}=97)$.

Berdasarkan tabel 1 menunjukkan Karakteristik lansia dilihat dari segi umur paling banyak kategori elderly kisaran umur 6074 tahun yang berjumlah 76 orang $(78,4 \%)$. Karakteristik lansia dilihat dari segi jenis kelamin, sebagian besar adalah lansia berjenis kelamin perempuan sebanyak 70 orang $(72,2 \%)$. Ditinjau dari status perkawinan lansia paling banyak lansia dengan status kawin sejumlah 51 orang $(52,6 \%)$. wilayah kerja Puskesmas Pampang. Kemudian dilakukan analisa data yakni dengan analisa univariat untuk menjelaskan karakteristik masingmasing variabel yang dimiliki. 
Berdasarkan tabel 2 menunjukkan bahwa status mental lansia pada umumnya normal yakni sebesar 54 orang $(55,7 \%)$ dan terdapat 29 orang $(29,9 \%)$ mengalami gangguan status mental ringan.

\section{Status Mental lansia berdasarkan usia}

\begin{tabular}{lcc}
\hline \multicolumn{1}{c}{ Status Mental Lansia } & n & \% \\
\hline Normal & 54 & 55,7 \\
Gangguan status mental ringan & 29 & 29,9 \\
Gangguan status mental berat & 14 & 14,4 \\
\hline \multicolumn{1}{c}{ Total } & $\mathbf{9 7}$ & $\mathbf{1 0 0}$ \\
\hline
\end{tabular}

Tabel 3 Distribusi frekuensi Status Mental Lansia Berdasarkan Usia Lansia diwilayah kerja Puskesmas Pampang.

\section{PEMBAHASAN}

Dalam penelitian ini, status mental lansia di kategorikan menjadi 3 bagian yaitu normal, gangguan status mental ringan dan gangguan status mental berat. Berdasarkan riset ini ditemukan bahwa status mental lansia diwilayah kerja Puskesmas Pampang mayoritas memiliki statusmental normal yakni 55,7\%, akan tetapi masih ada $44,3 \%$ yang mengalami gangguan status mental terdiri dari gangguan status mental ringan sebesar 29,9\% dan gangguan status mental berat terdapat $14,4 \%$.

Hal ini dikaitkan dengan teori pola perilaku yang akan berubah berkaitan dengan peningkatan usia. Komponen yang berperan dalam ranah ini adalah kemampuan beradaptasi yang terdiri dari memori, perasaan, pengetahuan, kecerdasan, dan motivasi lansia (Tamher \& Noorkasiani, 2009). Pada umumnya lansia yang dapat menyesuaikan diri akan mampu mempertahankan kondisi mental yang normal namun jika lansia tidak memiliki koping yang baik dalam menghadapi kondisi tersebut maka dapat terjadi gangguan psikologi berupa penurunan status mental pada lansia.

Dibuktikan dari hasil kuesioner yang menunjukkan orientasi waktu responden sangat rendah yakni $61,9 \%$ dari responden tidak dapat menyebutkan waktu dengan tepat. Dari hasil tesebut tampak lansia tidak mampu beradaptasi dengan perubahan kondisi yang dibuktikan dengan terjadinya disfungsi memori pada sebagian lansia.

Penyebab dari masalah ini adalah pandangan lansia akan menyempit dalam berbagai hal yang dikaitkan dengan kemunduran fungsi ingatan di lobus frontalis dan serebelum (Tamher \& Koorsiani 2009). Selain itu dijelaskan dalam artikel penelitian Eka, Suwandi \& Komalasari (2010) pada lansia yang mengalami gangguan status mental, hasil dari registrasi dan kalkulasi mereka kurang disertai dengan pendidikan yang rendah atau bahkan ada responden yang tidak pernah bersekolah.

Status mental lansia ditinjau dari usia responden didapatkan bahwa status mental normal mayoritas dimiliki oleh lansia kategori elderly (60-74 tahun) yakni 48 lansia (63,2\%). Lansia pada usia elderly (60-74 tahun) masih memiliki kemampuan untuk bersosialisasi sehingga dapat berpartisipasi sebaga iresponden. Pada usia ini lansia masih memiliki fungsi kognitif yang baik. Hal ini dibuktikan dengan respon ketika dilakukan interview dengan kuesioner mampu dijawab secara tepat. Semakin bertambahnya usia menuju kategori Old (usia 75-90 tahun) lansia seharusnya akan mengalami penurunan status mental dibandingkan kategori elderly. Namun dalam penelitian ini masih terdapat 30\% lansia (usia 75-90 tahun) yang memiliki status mental yang normal. Hal ini berarti lansia yang 
terdapat dalam 30\% tersebut memiliki koping yang baik dalam menyesuaikan diri terhadap perubahan proses penuaan yang terjadi sehingga dapat mempertahankan status mental dalam keadaan normal.

Adapun lansia yang termasuk dalam kategori Very Old ( $>90$ tahun) mengalami gangguan status mental yang ringan. Hal ini menunjukkan lansia pada usia tersebut mengalami penurunan fungsi fisik maupun mentalnya sehingga lebih mudah mengalami gangguan mental. Selain itu, dari hasil kuesioner yakni MMSE menunjukkan bahwa lansia dengan gangguan fungsi kognitif ringan maupun berat tidak dapat menjawab pertanyaan dengan tepat sehingga memiliki poin yang kurang dibagian registrasi, membaca, menulis dan menggambar.

\section{KESIMPULAN}

Berdasarkan hasil penelitian ini maka dapat disimpulkan bahwa: Karakteristik responden lansia dilihat dari segi umur paling banyak kategori elderly (umur 60-74 tahun) sebesar $78,4 \%$. Sebagian besar lansia berjenis kelamin perempuan $(72,2 \%)$. Lansia paling banyak dengan status kawin $(52,6 \%)$. Tingkat pendidikan lansia mayoritas tidak tamat SD sejumlah 48 orang $(49,5 \%)$. Adapun riwayat pekerjaan lansia pada umumnya IRT dengan jumlah 47 lansia $(48,5)$. Sebagian besar lansia tidak memiliki riwayat penyakit $(21,6 \%)$. Adapun penyakit tersering dijumpai pada responden yakni rematik sebanyak 18 orang $(18,6 \%)$.

Status mental lansia di wilayah kerja Puskesmas Pampang pada umumnya normal yakni $55,7 \%$, namun demikian terdapat $29,9 \%$ yang mengalami gangguan status mental ringan dan sebesar $14,4 \%$ dideteksi gangguan status mental berat. Sedangkan status mental berdasarkan karakteristik lansia yaitu ditinjau dari usia, lansia very old yaitu > 90 tahun $100 \%$ mengalami gangguan status mental (100\%).

\section{DAFTAR PUSTAKA}

A.Tomb, D. (2004). Buku Saku Psikiatrik Edisi 6. Jakarta: EGC.

Adicondro, N. (2014). Pengaruh Terapi Kelompok Reminiscence untuk Menurunkan Tingkat Depresi Pada Lanjut Usia Di Panti Sosial Tresna Werdha Unit Budi Luhur Kasongan, Bantul, Daerah Istimewa Yogyakarta. Yogyakarta: Universitas Ahmad Dahlan.

Agronin, M. E., \& Maletta, G. J. (2011). Principles and Practice of Geriatric Psychiatry. USA: Lippincontt Williams \& Wilkins.

Astuti, D. F. (2013). The Correlation Between Mental Status and Elimination Patern of Elderly at Budi Luhur Nursing Home Kasongan Bangunjiwo Kasihan Bantul Yogyakarta. Sekolah Tinggi Ilmu Kesehatan 'Asyiyah: Yogyakarta.

Banon, Endang. (2011). Pengaruh Terapi Reminiscence dan Psikoedukasi Keluarga Terhadap Kondisi Depresi dan Kualitas Hidup Lansia. Depok: UI.

Badan Penelitian Statistik (BPS). (2013). Proyeksi Penduduk Indonesia 2010-2035. Jakarta: Badan Penelitian Statistik

Badan Penelitian Statistik (BPS). (2015). Statistik Penduduk Lanjut Usia. Jakarta: Badan Pusat Statistik.

Balqis, U. M., \& Wati, D. N. (2014). Penurunan Fungsi Kognitif Berhubungan dengan Ketidakmandirian Lansia di Panti Sosual dalam Melakukan Aktivitas Kehidupan Seharihari. Depok: Universitas Indonesia.

Baughman, D. C., \& Hackley, J. C. (2000). Keperawatan Medikal-Bedah Buku Saku Brunner \& Suddarth. Jakarta: EGC.

BkkbN. (2012). Pembinaan Mental Emosional Pada Lansia. Jakarta : Direktorat bina Ketahanan Keluarga Lansia dan Reantan Badan Kependudukandan Keluarga Berencana Nasional.

Brizendine, L. (2007). The Female Brain. Jakarta Selatan: Ufuk Press.

Comer, S. (2005). Geriatric Nursing Care Plans. Canada: Thomson Delmar Learning, a part of the Thomson Corporation. Thomson, the Star logo, and Delmar Learning are trademarks used herein under license.

Coresa, T. (2010). Gambaran Fungsi Kognitif Pada Lansia Di Unit Rehabilitasi Sosial Pucang Gading Semarang. Semarang: FK UNDIP.

Dahlan, M. S. (2008). Statistik untuk Kedokteran dan Kesehatan. Jakarta: Salemba Medika.

Davey, P. (2005). At a Glance Medicine. Jakarta: Erlangga.

Davies, T., \& Craig, T. (2009). ABC Kesehatan Mental. Jakarta: EGC.

Dayamaes, R. (2013). Gambaran Fungsi Kognitif Klien Usia Lanjut di Posbindu Rosella Legoso Wilayah Kerja Puskesmas Ciputat Timur Tangeran Selatan. 
Jakarta: Universitas Islam Negeri Syarif Hidayatullah.

Dewanto, G., Suwono, W. J., Riyanto, B., \& Taruna, Y. (2009). Panduan Praktik Diagnosis dan Tatalaksana Penyakit Saraf. Jakarta: EGC.

Dewi, S. R. (2014). Buku Ajar Keperawatan Gerontik. Yogyakarta: Deepublish.

Dinas Kesehatan Makassar. (2014). Profil Kesehatab Kota Makasaar 2013. Makassar: Pemerintah Kota Makassar Dinas Kesehatan .

Efendi, F., \& Makhfudi. (2009). Keperawatan Kesehatan Komunitas: Teori dan Praktik dalam Keperawatan. Jakarta: Salemba Medika.

Eka, N. G., Suwandi, Y., \& Komalasari, R. (2010, Maret). Analisis Hubungan antara Latihan Fisik dan Status Kognitif pada Lansia Di Posyandu Melati VII Puskesmas Kelapa Dua Tangerang. Medicunus Vol. 3 No. 4 Maret 2010- Juni 2010, pp. 11-19.

Eliopoulos, C. (2014). Gerontological Nursing . China: Lippincott Williams \& Wilkins.

Fortinash, \& Worret, H. (2012). Psychiatric Mental Health Nursing. USA: Elsevier Mosby.

Fratantoro, C. A. (2011). Occupation Therapy in Mental Health. USA: F. A. Davis Company.

Ginsberg, L. (2007). Neurologi Edisi 8. Jakarta: Erlangga.

Gulo, W. (2000). Metode Penelitian. Jakarta: Grasindo.

Hamdi, A. S., \& Baharuddin, E. (2014). Metode Penelitian Kuantitatif Aplikasi dalam Pendidikan. Yogyakarta: Deepublish.

Handayani, S. (2012). Efektifitas Terapi Religi terhadap Penurunan Tingkat Stress. Klaten: Stikes Muhammdiyah Klaten.

Handayani, T., Maulida, M., \& Rachma, N. (2013). Pesantren Lansia sebagai Upaya Meminimalkan Risiko Penurunan Fungsi Kognitif di Balai Rehabilitasi Sosial Lansia Unit II Pucang Gading Semarang. Jurnal Keperawatan Komunitas . Volume 1, No. 1, Mei 2013; 1-9 , 1-9.

Hanifa, A. (2016). Hubungan Kualitas Tidur dan Fungsi Kognitif Pada Lanjut Usia di Panti Sosial Margaguna Jakarta Selatan. Jakarta: Universitas Islam Negeri Syarif Hidayatullah.

Hartono, B. (2008). Metode Penelitian Kesehatan Dengan Contoh Bidang Ilmu Kesehatan Gigi. Jakarta: EGC.

Hindle, A., \& Coates, A. (2011). Nursing People Care of Older People. New York: Oxford University Press.

Irawan, H. (2013). Gangguan Depresi pada Lanjut Usia. CDK-210/ vol. 40 no. 11, th 2013, 815-820

John, R. (2000). Mini-mental States Exam. Wshington DC: Psychiatric Measures.

Juliandi, A., Irfan, \& Manurung, S. (2014). Metodologi Penelitian Bisnis. Medan: Umsupress.
Katona, C., Cooper, C., \& Robertson, M. (2012). At a Glance Psiciatria. Jakarta: Erlangga.

KemenkesRI. (2014). Situasi dan Analisis Lanjut Usia. Jakarta: Kementrian Kesehatan RI.

Khairani. (2016). Gambaran Tipe Kesepian Lansia di Gampong Lamme Garot Kecamatan Montasikka Kabupaten Aceh Besar Tahun 2012. Jurnal Ilmu Keperawatan Vo. I No. 1 , 20-26.

Komisi Nasional Etik Penelitian Kesehatan (KNEPK). (2010). Komisi Nasional Etik Penelitian Kesehatan. Retrieved Oktober 5, 2016, from knepk.litbang.depkes: http://www.knepk.litbang.depkes.go.id/ knepk/

Kurlowicz, L. (1999, Januari 3). The Mini Mental State Examination (MMSE) from The Hartford Institute for Geriatric Nursing. Retrieved September 27, 2016, from www.mountsinai.on.ca: https://www. mountsinai.on.ca/care/psych/on-callresources/on-call-resources/mmse.pdf

Machfoedz, I. (2014). Metodologi Penelitian (Kuantitatif \& Kualitatif). Yogyakarta: Fitramaya.

Martono, H., \& Pranaka, K. (2010). Geriatri (Ilmu Kesehatan Usia Lanjut). Jakarta: Balai Penerbit FKUI.

Maryam, R. S., Ekasari, M. F., Rosidawati, Jubaedi, A., \& Batubara, I. (2008). Mengenal Usia Lanjut dan Perawatannya. Jakarta: Salemba Medika.

Mongisidi, R., Tumewah, R., \& Kembuan, M. A. (2012). Profil Penurunan Fungsi Kognitif pada Lansia di Yayasan-Yayasan Manula di Kecamatan Kawangkoan. Manado: Fakultas Kedokteran Universitas Sam Ratulangi.

Morgan, N. (2014). Pandua Stres Bagi Remaja. Gemilang: Jakarta.

Nugroho, W. (2009). Komunikasi dalam Keperawatan Gerontik. Jakarta: EGC.

Nursalam. (2008). Konsep dan Penerapan Metodologi Penelitian Ilmu Keperawatan. Jakarta: Salemba Medika.

Oktavia, N. (2015). Sistematika Penulisan Karya Ilmiah. Yogyakarta: Deepublish.

Patricia, \& Runcan, L. (2013). Depression in the Elderly. UK: Cambridge Scholars Publishing.

Perese, E. F. (2012). Psychiatric Advanced Practice Nursing. USA: E.A Davis Company.

Ponto, D. L., Bidjuni, H., \& Karundeng, M. (2015). Pengaruh Penerapan Terapi Okupasi Terhadap Penurunan Stres Pada Lansia Di Panti Werdha Damairanomuut Manado. ejournal Keperawatan (e-Kp) Volume 3. Nomor 2. Mei 2015 , 1-7.

Riani, S., Adi, H., \& Supriyono, M. (2013). Studi Deskriptif Status Mental Lansia Berdasarkan Karakteristik Lansia di Kelurahan Karangayu Semarang Barat. Semarang: Dinkes Semarang.

R.A, G. S., Indarwati, R., \& Has, E. M. (2014). 
Reminiscence Therapy with Therapeutic Methods Group Activity Improve Elderly's Cognitive Function. Surabaya: Universitas Airlangga.

Santoso, H., \& Ismail, A. (2009). Memahami Krisis Lanjut Usia. Jakarta: Gunung Mulia.

Saryono, \& Anggraeni, M. D. (2013). Metodologi Penelitian Kualitatif dan Kuantitatif dalam Bidang Kesehatan. Yogyakarta: Nuha Medika.

Segal, D. L., Qualls, S. H., \& Smyer, M. A. (2011). Aging and Mental Health. UK : Wiley-Blackwell

Sherwood, L. (2014). Fisiologi Manusia Dari Sel ke Sistem Edisi 8. Jakarta: EGC.

Sugiyono. (2015). Metode Penelitian Kuantitatif Kualitatif dan R\&D. Bandung: Alfabeta.

Suprajitno. (2004). Asuhan Keperawatan Keluarga Aplikasi dalam Praktik. Jakarta: EGC.

Suyoko. (2012). Faktor-Faktor Risiko yang Berhubungan dengan Gangguan Mental Emosional Pada Lansia di DKI Jakarta. Depok: Universitas Indonesia.

Swarjana, I. K. (2016). Statistik Kesehatan. Yogyakarta: Andi Offset.

Tamher, S., \& Noorkasiani. (2009). Kesehatan Usia Lanjut dengan Pendekatan Asuhan
Keperawatan. Jakarta: Salemba Medika.

UN. (2015). World Population Ageing. New York: United Nations

Wattis, J. P., \& Curran, S. (2006). Practical Psychiatry of Old Age. UK: Radcliffe Publishing.

WHO (World Health Organization). (2016, April). Mental Health and Older Adults. Dipetik September 23, 2016, dari World Health Organization: http://www.who.int/ mediacentre/factsheets/fs381/en/

Widyarini, N. (2009). Seri Psikologi Populer: Kunci Pengembangan Diri. Jakarta: PT Elex Media Komputindo.

Woods, B., Spector, A. E., Jones, C. A., Orrel, M., \& Davis, S. P. (2005, April 20). Reminiscence therapy for dementia. Cochrane Library .

Wreksoatmodjo, B. R. (2014). Beberapa Kondisi Fisik dan Penyakit yang Merupakan Faktor Risiko Gangguan Fungsi Kognitif. CDK-212/ vo. 41 no. 1, th 2014 , 25-32.

Zulfitri, R. (2011). Konsep Diri dan Gaya Hidup Lansia yang Mengalami Penyakit Kronis dI Panti Sosial Tresna Werdha (PSTW) Khusnul Khotimah Pekanbaru. Jumal Ners Indonesia, Vol. 1, No. 2, Maret 2011, 21-30 